\title{
Utredning av pasienter med akutt svimmelhet ved en nevrologisk avdeling
}

ORIGINALARTIKKEL

\section{MARTIN WEISSHAAR}

E-post: martin.weisshaar@sshf.no

Nevrologisk avdeling

Sørlandet sykehus, Kristiansand

Han har bidratt med idé, utforming og design, datainnsamling, analyse av data, tolking av data og litteraturs $ø \mathrm{k}$ samt utarbeiding, revisjon og godkjenning av innsendte manus.

Martin Weisshaar er spesialist i nevrologi, avdelingssjef og overlege.

Forfatteren har fylt ut ICMIE-skjemaet og oppgir ingen interessekonflikter.

\section{ÅSE MYGLAND}

Nevrologisk avdeling

Sørlandet sykehus, Kristiansand

og

Klinisk institutt 1

Universitetet i Bergen

og

Seksjon for voksenhabilitering

Sørlandet sykehus, Arendal

Hun har bidratt med idé, utforming og design, datainnsamling, analyse av data, tolking av data og litteratursøk samt utarbeiding, revisjon og godkjenning av innsendte manus.

Åse Mygland er spesialist i nevrologi, overlege og professor.

Forfatteren har fylt ut ICMJE-skjemaet og oppgir ingen interessekonflikter.

\section{UNN LJØSTAD}

Nevrologisk avdeling

Sørlandet sykehus, Kristiansand

og

Klinisk institutt 1

Universitetet i Bergen

Hun har bidratt med idé, utforming og design, datainnsamling, analyse av data, tolking av data og litteratursøk samt utarbeiding, revisjon og godkjenning av innsendte manus.

Unn Ljøstad er spesialist i nevrologi, overlege og professor.

Forfatteren har fylt ut ICMJE-skjemaet og oppgir ingen interessekonflikter. 


\section{BAKGRUNN}

Akutt svimmelhet kan ha mange årsaker, blant annet kan hjerneslag presentere seg som isolert akutt vestibulært syndrom. Akutt episodisk svimmelhet anbefales utredet med posisjonstester, og akutt vedvarende svimmelhet med fokus på testbatteriet HINTS (Head Impulse, Nystagmus, Test of Skew), som kan skille hjerneinfarkt fra vestibularisnevritt. Vi $\emptyset n s k e t$ å kartlegge forekomst, diagnosespekter og tilnærming til akutt svimmelhet på en nevrologisk avdeling.

\section{MATERIALE OG METODE}

Vi har foretatt en retrospektiv journalgjennomgang av alle pasienter med akutt svimmelhet som hovedsymptom som i 2015 ble innlagt på Nevrologisk avdeling ved Sørlandet sykehus, Kristiansand.

\section{RESULTATER}

Av totalt 2231 pasienter innlagt ved Nevrologisk avdeling i 2015 hadde 243 pasienter (11\%) svimmelhet som hovedsymptom. 106 pasienter (44\%) ble unders $ø$ kt med hele HINTS. Cerebral CT ble utført hos 213 (88\%) og MR hos 91 (37\%), og disse påviste aktuell patologi hos henholdsvis 1 og 4 pasienter. Ved utskriving fikk 122 pasienter (50 \%) en uspesifikk symptomdiagnose, 59 (24\%) fikk diagnosen vestibularisnevritt, 41 (17\%) benign paroksysmal posisjonsvertigo, og 5 ( $2 \%$ fikk diagnosen hjerneslag. Fire av fem med hjerneslag kunne retrospektivt klassifiseres som akutt vestibulært syndrom, hvorav tre hadde typiske funn på HINTS-undersøkelsen.

\section{FORTOLKNING}

Akutt svimmelhet er et vanlig symptom ved innleggelse i nevrologisk avdeling. Kunnskapsbaserte diagnostiske anbefalinger ved utredning av akutt svimmelhet var ikke tilfredsstillende implementert i praksis.

Akutt svimmelhet, definert som svimmelhet oppstått i løpet av sekunder til timer, er en vanlig grunn til innleggelse i sykehus. Tidlig og presis årsaksdiagnostikk er viktig, men utfordrende. Årsaksspekteret er stort (1-3), og alvorlige årsaker som trenger raske tiltak, for eksempel hjerneslag i bakre kretsløp, kan til forveksling likne ufarlige tilstander som ikke trenger innleggelse (4-6). Systematisk diagnostisk tilnærming er derfor viktig for å iverksette riktig behandling til riktig tid.

Tradisjonell utredning av akutt svimmelhet har hatt fokus på å kartlegge svimmelhetens kvalitet, avdekke ledsagende nevrologiske utfall, og se etter hjerneslag med cerebral CT (7-9). En slik tilnærming har imidlertid begrenset diagnostisk treffsikkerhet. Anamnestiske opplysninger om svimmelhetens kvalitet er lite egnet til å skille mellom alvorlige og mindre alvorlige årsaker (7). Hjerneslag i bakre kretsløp kan presentere seg som isolert svimmelhet uten ledsagende nevrologiske utfall (10-14), og færre enn $10 \%$ av hjerneinfarktene i bakre kretsløp er synlige på cerebral CT i tidlig fase $(15,16)$.

De siste ti årene har det kommet flere kunnskapsbaserte anbefalinger for diagnostisk tilnærming til pasienter med akutt svimmelhet (17-20). Hovedbudskapet i disse anbefalingene er at man bør skille mellom episodisk og vedvarende svimmelhet, identifisere pasienter med akutt vestibulært syndrom, kartlegge triggere, og gjøre målrettet, trinnvis undersøkelse med kliniske otonevrologiske tester.

Akutt vestibulært syndrom defineres som akutt oppstått og vedvarende svimmelhet med ledsagende kvalme, bevegelsesintoleranse og nystagmus. Den vanligste årsaken til akutt vestibulært syndrom er vestibularisnevritt, men opptil $25 \%$ skyldes slag i bakre kretsløp (4). Det er viktig å skille mellom disse to tilstandene. En tretrinns øyemotilitetsundersøkelse kalt HINTS (Head Impulse, Nystagmus, Test of Skew) kan brukes til det formålet (tabell 1). 
Test av vertikal skjeling (test of skew) kalles også tildekkingstest (cover test), og utføres ved at undersøkeren dekker pasientens ene øye i minst fem sekunder med hånden. Pasienten blir bedt om å se på undersøkerens ene øye. Hånden tas vekk, og en observerer om det avdekkede øyet gjør en vertikal innstillingsbevegelse. I en studie var HINTS bedre egnet enn tidlig MR til å skille hjerneslag fra vestibularisnevritt hos pasienter med akutt vestibulært syndrom og minst én slagrisikofaktor (17). HINTS er en rask og enkel undersøkelse, men krever litt trening både for utførelse og tolkning.

\section{Tabell 1}

HINTS-test (Head Impulse, Nystagmus, Test of Skew). Testen kan brukes til å skille mellom vestibularis nevritt og hjerneslag hos en pasient ved akutt vestibulært syndrom (17).

\begin{tabular}{|lll|}
\hline Undersøkelser & $\begin{array}{l}\text { Taler for vestibularisnevritt } \\
\text { (hvis alle er oppfylt) }\end{array}$ & $\begin{array}{l}\text { Taler for hjerneslag } \\
\text { (hvis én er oppfylt) }\end{array}$ \\
\hline Hodeimpulstest & $\begin{array}{l}\text { Refikseringssakkade ved } \\
\text { hodevridning mot sykt øre }\end{array}$ & $\begin{array}{l}\text { Ingen refikseringssakkade } \\
\text { (normal) }\end{array}$ \\
\hline Nystagmus & $\begin{array}{l}\text { Primær horisontal-rotatorisk, } \\
\text { skifter ikke retning }\end{array}$ & $\begin{array}{l}\text { Primær vertikal eller } \\
\text { rotatorisk, eller skifter retning }\end{array}$ \\
\hline $\begin{array}{l}\text { Test av vertikal } \\
\text { skjeling (test of skew) }\end{array}$ & Ingen vertikal skjeling & $\begin{array}{l}\text { Vertikal skjeling (ev. bare ved } \\
\text { tildekkingstest) }\end{array}$ \\
\hline
\end{tabular}

Episodisk svimmelhet som trigges av hodebevegelser, bør utredes med posisjonstesting med tanke på benign paroksysmal posisjonsvertigo. Ved spontan episodisk svimmelhet er det viktig å vurdere transitorisk iskemisk attakk som mulig årsak.

Ved Sørlandet sykehus i Kristiansand blir de fleste pasienter med akutt oppstått svimmelhet innlagt i Nevrologisk avdeling, blant annet fordi slag er en mulig underliggende årsak. Egen klinisk erfaring og funn i tidligere studier (7-9) gir grunn til å tro at kunnskapsbaserte anbefalinger for årsaksdiagnostikk av akutt svimmelhet i liten grad er tatt i bruk. Målet med denne studien var å undersøke forekomst og diagnosespekter ved akutt svimmelhet på en generell nevrologisk avdeling og å kartlegge bruk av kunnskapsbaserte prinsipper for årsaksutredning.

\section{Materiale og metode}

Studien er basert på en retrospektiv journalgjennomgang av pasienter innlagt akutt på Nevrologisk avdeling ved Sørlandet sykehus, Kristiansand, i 2015. Pasienter med svimmelhet som hovedsymptom ble identifisert ved søk i epikrise etter ICD-1o-kodene H81 (forstyrrelser i vestibularisfunksjonen), H82 (svimmelhetssyndromer ved sykdommer klassifisert annet sted), H83.o-H83.3 (andre sykdommer i indre øre) og R42 (svimmelhet). I tillegg ble journalene til alle med svimmelhet som innleggelsesdiagnose gjennomgått. Pasienter hvis journalopplysninger bekreftet at akutt svimmelhet var dominerende symptom, ble inkludert. Kjønn, alder, utskrivingsdiagnoser, liggetid, relevante anamnestiske opplysninger, kliniske og otonevrologiske funn og radiologisk diagnostikk ble registrert.

Nevrologisk avdeling i Kristiansand har 22 senger (15 nevrologi- og 7 slagsenger). Akutt innlagte pasienter tas imot av LIS1-lege eller lege i spesialisering i nevrologi. Alle akuttinnlagte pasienter blir tilsett av vakthavende lege i spesialisering i nevrologi. Avdelingen har ansvar for alle nevrologiske innleggelser i Vest- og Aust-Agder og de fleste hjerneslagpasienter i Vest-Agder, mens hjerneslagpasienter fra Aust-Agder legges inn på sykehus i Arendal, og hjerneslagpasienter fra vestlige deler av Vest-Agder legges inn på sykehuset i Flekkefjord. Det bor om lag 230 ooo voksne personer i avdelingens nedslagsfelt. Ved Sørlandet sykehus legges pasienter med akutt svimmelhet vanligvis inn på Nevrologisk avdeling i Kristiansand, men unntaksvis kan noen i studieperioden ha blitt lagt inn på slagavdelingene i Arendal eller Flekkefjord eller på medisinsk avdeling eller øre-nesehalsavdeling. Studien ble vurdert som kvalitetssikringsprosjekt av Regionale komiteer for 
medisinsk og helsefaglig forskningsetikk, og ble godkjent av Norsk senter for forskningsdata.

\section{Resultater}

I 2015 var det totalt 2231 innleggelser på Nevrologisk avdeling i Kristiansand, hvorav over $95 \%$ var akutte. Av disse var det 243 pasienter som fylte inklusjonskriteriene. Tre pasienter ble utskrevet fra akuttmottaket etter poliklinisk vurdering. Vi kan dermed grovt estimere at pasienter med akutt svimmelhet som hovedsymptom utgjorde $11 \%$ av alle innleggelsene. Varigheten av innleggelsene var gjennomsnittlig 1,9 døgn (SD 1,3) og median $1 \mathrm{~d} ø g n$ (spredning o-8). Median alder var 59 år (spredning 19-94 år), og 151 (62 \%) var kvinner.

Tabell 2 viser diagnosespekteret. Ved utskriving fikk 122 (50\%) av pasientene en symptomdiagnose: R42 (svimmelhet) eller H81.9 (uspesifisert forstyrrelse i vestibularisfunksjonen).

\section{Tabell 2}

Endelig diagnose i epikrise for 243 pasienter innlagt i 2015 ved Sørlandet sykehus, Kristiansand, med akutt svimmelhet som hovedsymptom.

\begin{tabular}{|lrr|}
\hline Utskrivingsdiagnose & \multicolumn{2}{c|}{$\mathbf{n}(\%)$} \\
\hline Svimmelhet & 112 & $(46)$ \\
\hline Vestibularisnevritt & 59 & $(24)$ \\
\hline Benign paroksysmal posisjonsvertigo & 41 & $(17)$ \\
\hline Uspesifisert perifer vestibulopati & 10 & $(4)$ \\
\hline Hjerneslag & 5 & $(2)$ \\
\hline Andre $^{1}$ & 16 & $(7)$ \\
\hline
\end{tabular}

${ }^{1} \mathrm{~F} \emptyset$ lgende diagnoser forekom tre eller færre ganger: Ménières sykdom, pneumoni, synkope/nærsynkope, hodepine, migrene med aura, karotisstenose uten hjerneslag, ustø gange, multippel sklerose og episodisk paroksysmal angst.

Tabell 3 gir en oversikt over kliniske undersøkelser dokumentert i pasientjournalene. Hos 194 pasienter (8o \%) var svimmelhetens kvalitet (for eksempel rotatorisk, nautisk, uspesifikk) beskrevet. Begrepet akutt vestibulcert syndrom var ikke brukt i noen av journalene, eventuelle triggere var mangelfullt beskrevet, og klassifisering i episodisk eller vedvarende svimmelhet var mangelfull. Ved retrospektiv journalgjennomgang ble svimmelheten klassifisert som episodisk hos 47 pasienter (19\%), vedvarende hos 193 (79\%), og ukjent hos 3 ( $1 \%$ ). Hos til sammen 72 pasienter (30\%) kunne svimmelheten retrospektivt klassifiseres som akutt vestibulært syndrom, av disse var kun $9(13 \%)$ fullstendig unders $ø$ kt med HINTStesten, mens $32(44 \%)$ ble undersøkt med posisjonstester selv om anamnesen ikke passet med benign paroksysmal posisjonsvertigo. Hos $10 \%$ av dem som fikk diagnosen vestibularisnevritt, var ikke hodeimpulstest dokumentert i journalen, og hos $17 \%$ av dem som fikk diagnosen benign paroksysmal posisjonsvertigo, var ikke posisjonstesting dokumentert i journalen.

\section{Tabell 3}

Kliniske undersøkelser dokumentert i pasientjournal for 243 pasienter innlagt i 2015 ved Sørlandet sykehus, Kristiansand, med akutt svimmelhet som hovedsymptom. Mer enn én undersøkelse kan være utført for hver pasient. (HINTS = Head Impulse, Nystagmus, Test of Skew.) 


\begin{tabular}{|lrc|}
\hline Kliniske undersøkelser & \multicolumn{2}{c|}{ n (\%) } \\
\hline Nystagmus' & 236 & $(97)$ \\
\hline Hodeimpulstest & 173 & $(71)$ \\
\hline Dix-Hallpikes test eller andre posisjonstester & 138 & $(57)$ \\
\hline HINTS fullstendig & 106 & $(44)$ \\
\hline Bruk av Frenzel-briller & 33 & $(14)$ \\
\hline Test av vertikal skjeling (test of skew) & 28 & $(12)$ \\
\hline
\end{tabular}

${ }^{1}$ Nystagmus var ikke nærmere beskrevet hos 71 pasienter.

Cerebral CT og MR ble utført hos henholdsvis 213 (88\%) og 91 (37\%) av pasientene. Relevant aktuell patologi ble påvist hos henholdsvis én og fire av disse. Av disse hadde én pasient cerebellær blødning som først ble påvist på CT og så på MR. Tre pasienter fikk påvist infarkt i bakre kretsløp på MR. Alle disse tre tok CT først. En pasient som ikke kunne ta MR, fikk diagnosen hjerneinfarkt på klinisk grunnlag.

Hos én av pasientene med hjerneinfarkt på MR var svimmelheten gått over før ankomst på akuttmottak, og det var kun vedvarende lett redusert finmotorikk. Retrospektivt kunne den kliniske presentasjonen klassifiseres som spontan episodisk svimmelhet. De to andre pasientene med hjerneinfarkt påvist på MR presenterte seg med isolert akutt vestibulært syndrom med normal hodeimpulstest.

\section{Diskusjon}

Mer enn hver tiende innlagte pasient ved vår nevrologiske avdeling i 2015 hadde svimmelhet som hovedsymptom. Årsaksdiagnostikk er avgjørende for valg av behandling. I vår studie fikk halvparten av pasientene en symptomdiagnose, og den resterende halvparten en årsaksdiagnose. Andelen pasienter med årsaksdiagnose i denne studien er betydelig lavere enn de om lag tre fjerdedeler som ble funnet i en amerikansk studie av 9 472 pasienter med akutt svimmelhet (2). Retrospektivt vurdert var den diagnostiske tilnærmingen i vår studie preget av stort fokus på svimmelhetens karakter, ikke-systematisk bruk av kliniske undersøkelser og høyt forbruk av CT-undersøkelser.

Funnene bekrefter at svimmelhet er et vanlig symptom som må håndteres daglig av en nevrolog i vakt, men at årsaksdiagnostikken er litt tilfeldig og i begrenset grad basert på kunnskapsbaserte anbefalinger.

Svimmelhetens kvalitet ble kartlagt hos hele $80 \%$ av pasientene til tross for at det har lav diagnostisk verdi $(7,8)$, mens kartlegging av tidsforløp, triggere og identifisering av pasienter med akutt vestibulært syndrom var mangelfull til tross for at dette har høy diagnostisk verdi $(4,14)$. Videre var det ofte dårlig sammenheng mellom anamnese og valg av tester. For eksempel ble HINTS-testen fullstendig utført hos kun 9 av 72 pasienter (13\%) som retrospektivt kunne klassifiseres som å ha akutt vestibulært syndrom. Derimot ble nesten halvparten av dem undersøkt med posisjonstester som bare anbefales ved mistanke om benign paroksysmal posisjonsvertigo. Hos flere av pasientene som fikk diagnosen vestibularisnevritt eller benign paroksysmal posisjonsvertigo, manglet dessuten dokumentasjon om hvilke funn diagnosene var basert på. Et enkelt hjelpemiddel som Frenzel-briller, som kan være nyttig både til å avdekke og karakterisere nystagmus, ble bare dokumentert brukt hos $14 \%$.

Akutt CT-undersøkelse ble gjort hos $88 \%$ av pasientene og viste relevant aktuell patologi hos kun én pasient i form av cerebellær blødning. CT egner seg ikke til å utelukke akutt hjerneinfarkt $(15,16)$, men er nødvendig for å utelukke hjerneblødning hos pasienter som vurderes for trombolyse, selv om intracerebral blødning er en svært sjelden årsak til isolert svimmelhet (21). 91 pasienter (37\%) ble undersøkt med slag-MR, hvorav tre undersøkelser viste akutt hjerneinfarkt, og én bekreftet cerebellær blødning som allerede var påvist på CT. Vestibularisnevritt og benign paroksysmal posisjonsvertigo kan diagnostiseres klinisk uten radiologiske undersøkelser. Pasienter med disse diagnosene utgjorde 31 \% i materialet vårt. 
Tallene tyder på at en god del pasienter ble utsatt for unødvendig CT-undersøkelse. Dette er i samsvar med andre studier som viser overforbruk av CT hos pasienter med akutt svimmelhet $(8,16)$.

4 av totalt 243 pasienter ( $2 \%$ og 3 av 72 pasienter med akutt vestibulært syndrom (4\%) fikk diagnosen hjerneinfarkt i epikrisen. Våre funn er sammenliknbare med en studie fra 2014 (6), hvor man fant hjerneslag hos $3 \%$ av alle pasienter med akutt svimmelhet. Tall i litteraturen ellers varierer betydelig. En oversikt fra Tarnutzer og medarbeidere (4) anslår høye mørketall og at $10-20 \%$ av alle pasienter med akutt svimmelhet og inntil $25 \%$ av alle med akutt vestibulært syndrom har hjerneslag.

Hos tre av våre fire pasienter som fikk diagnosen hjerneinfarkt, presenterte tilstanden seg som akutt vestibulært syndrom. Alle tre hadde funn på HINTS-undersøkelsen forenlig med hjerneslagmistanke. En av pasientene med hjerneinfarkt var symptomfri ved ankomst og kunne retrospektivt klassifiseres som spontan episodisk svimmelhet. Ved spontan episodisk svimmelhet skal man ifølge anbefalingene mistenke transitorisk iskemisk attakk dersom det ikke finnes annen åpenbar forklaring, og særlig dersom pasienten har vaskulære risikofaktorer.

En pasient med blødning i cerebellum presenterte seg med akutt vestibulært syndrom, men hadde også andre nevrologiske utfall, og tilstanden kunne ikke klassifiseres som isolert svimmelhet.

En systematisk tilnærming i tråd med tilgjengelige anbefalinger (17-19), ville ha gitt sterk klinisk mistanke om cerebrovaskulær årsak hos alle våre fem pasienter med hjerneslag. Samtidig tror vi at anvendelse av kunnskapsbaserte anbefalinger ville ha medført noen flere hjerneslagsdiagnoser i vår studiepopulasjon, og sannsynligvis færre CT-undersøkelser. Vi tror også at det kunne bidratt til tidligere diagnostikk av ufarlige årsaker til akutt svimmelhet som for eksempel vestibularisnevritt og benign paroksysmal posisjonsvertigo, og at flere enn tre pasienter kunne vært utskrevet direkte fra akuttmottak.

Studien var ikke designet for å se på årsaken til at implementeringen av kunnskapsbaserte anbefalinger ikke var tilfredsstillende. Sannsynligvis var anbefalingene lite kjent, selv om de delvis var gjengitt i nevrologiske veiledere og elektronisk prosedyrebok (Akuttveileder for nevrologi og NevroNEL). Etter vår mening avspeiler dette at det er vanskelig for den enkelte lege å holde seg oppdatert til enhver tid. For at ny kunnskap skal komme pasientene til gode er det nødvendig at vitenskapelige publikasjoner omsettes til kliniske råd og algoritmer som er enkle i bruk og lett tilgjengelige, og at disse kombineres med repetert undervisning i praktiske kliniske ferdigheter.

Styrken ved vår undersøkelse er at vi har inkludert alle pasienter med akutt svimmelhet i et helt år, og at resultatene reflekterer hvordan vi jobber i en vanlig, travel klinisk hverdag. Svakheten er en retrospektiv design. Når man bruker journalnotater som kilde, får man kun registrert det som er skriftlig dokumentert. Det kan derfor ikke utelukkes at reelt antall utførte kliniske undersøkelser avviker noe fra det som er angitt i resultatene våre.

\section{Konklusjon}

Akutt svimmelhet er vanlig i en generell nevrologisk avdeling. Hjerneslag kan presentere seg som isolert svimmelhet. Nye kunnskapsbaserte anbefalinger for årsaksdiagnostikk var lite brukt. Studien er en nyttig påminnelse om at publiserte anbefalinger ikke automatisk medfører endringer i rutiner. Implementering av ny kunnskap, blant annet i form av oppdaterte prosedyrer og internundervisning, er en egen oppgave som bør prioriteres i dagens helsevesen. 
Nevrologisk avdeling ved Sørlandet sykehus, Kristiansand, i 2015.

Diagnostisk tilnærming til denne pasientgruppen var preget av ikke-systematisk bruk av kliniske undersøkelser og høyt forbruk av CT-undersøkelser.

Studien avdekket behov for implementering av nye, kunnskapsbaserte anbefalinger for diagnostikk ved akutt svimmelhet.

\section{LITTERATUR:}

1. Saber Tehrani AS, Coughlan D, Hsieh YH et al. Rising annual costs of dizziness presentations to U.S. emergency departments. Acad Emerg Med 2013; 20: 689-96. [PubMed][CrossRef]

2. Newman-Toker DE, Hsieh YH, Camargo CA et al. Spectrum of dizziness visits to US emergency departments: cross-sectional analysis from a nationally representative sample. Mayo Clin Proc 2008; 83: 765-75. [PubMed][CrossRef]

3. Royl G, Ploner CJ, Leithner C. Dizziness in the emergency room: diagnoses and misdiagnoses. Eur Neurol 2011; 66: 256-63. [PubMed][CrossRef]

4. Tarnutzer AA, Berkowitz AL, Robinson KA et al. Does my dizzy patient have a stroke? A systematic review of bedside diagnosis in acute vestibular syndrome. CMAJ 2011; 183: E571-92. [PubMed][CrossRef]

5. Newman-Toker DE, Moy E, Valente E et al. Missed diagnosis of stroke in the emergency department: a cross-sectional analysis of a large population-based sample. Diagnosis (Berl) 2014; 1: 155-66. [PubMed][CrossRef]

6. Chase M, Goldstein JN, Selim MH et al. A prospective pilot study of predictors of acute stroke in emergency department patients with dizziness. Mayo Clin Proc 2014; 89: 173-80. [PubMed][CrossRef]

7. Newman-Toker DE, Cannon LM, Stofferahn ME et al. Imprecision in patient reports of dizziness symptom quality: a cross-sectional study conducted in an acute care setting. Mayo Clin Proc 2007; 82: 1329-40. [PubMed][CrossRef]

8. Kerber KA, Newman-Toker DE. Misdiagnosing Dizzy Patients: Common Pitfalls in Clinical Practice. Neurol Clin 2015; 33: 565-75, viii. [PubMed][CrossRef]

9. Kerber KA, Morgenstern LB, Meurer WJ et al. Nystagmus assessments documented by emergency physicians in acute dizziness presentations: a target for decision support? Acad Emerg Med 2011; 18: 619-26. [PubMed][CrossRef]

10. Kim GW, Heo JH. Vertigo of cerebrovascular origin proven by CT scan or MRI: pitfalls in clinical differentiation from vertigo of aural origin. Yonsei Med J 1996; 37: 47-51. [PubMed][CrossRef]

11. Lee H, Sohn SI, Cho YW et al. Cerebellar infarction presenting isolated vertigo: frequency and vascular topographical patterns. Neurology 2006; 67: 1178-83. [PubMed][CrossRef]

12. Saber Tehrani AS, Kattah JC, Mantokoudis G et al. Small strokes causing severe vertigo: frequency of false-negative MRIs and nonlacunar mechanisms. Neurology 2014; 83: 169-73. [PubMed][CrossRef]

13. Lee H. Isolated vascular vertigo. J Stroke 2014; 16:124-30. [PubMed][CrossRef]

14. Venhovens J, Meulstee J, Verhagen WI. Acute vestibular syndrome: a critical review and diagnostic algorithm concerning the clinical differentiation of peripheral versus central aetiologies in the emergency department. J Neurol 2016; 263: 2151-7. [PubMed][CrossRef]

15. Ozono Y, Kitahara T, Fukushima M et al. Differential diagnosis of vertigo and dizziness in the emergency department. Acta Otolaryngol 2014; 134:140-5. [PubMed][CrossRef]

16. Wasay M, Dubey N, Bakshi R. Dizziness and yield of emergency head CT scan: is it cost effective? Emerg Med J 2005; 22:312. [PubMed][CrossRef]

17. Kattah JC, Talkad AV, Wang DZ et al. HINTS to diagnose stroke in the acute vestibular syndrome: three-step bedside oculomotor examination more sensitive than early MRI diffusion-weighted imaging. Stroke 2009; 40:3504-10. [PubMed][CrossRef]

18. Kerber KA, Baloh RW. The evaluation of a patient with dizziness. Neurol Clin Pract 2011; 1: 24-33. [PubMed][CrossRef] 
19. Vanni S, Pecci R, Casati C et al. STANDING, a four-step bedside algorithm for differential diagnosis of acute vertigo in the Emergency Department. Acta Otorhinolaryngol Ital 2014;34: 419-26. [PubMed] 20. Newman-Toker DE, Edlow JA. TiTrATE: A Novel, Evidence-Based Approach to Diagnosing Acute Dizziness and Vertigo. Neurol Clin 2015;33: 577-99, viii. [PubMed][CrossRef]

21. Kerber KA, Burke JF, Brown DL et al. Does intracerebral haemorrhage mimic benign dizziness presentations? A population based study. Emerg Med J 2012; 29: 43-6. [PubMed][CrossRef]

Publisert: 2. oktober 2019. Tidsskr Nor Legeforen. DOI: 10.4045/tidsskr.18.o820 Mottatt 21.10.2018, første revisjon innsendt 14.2.2019, godkjent 18.6.2019.

(C) Tidsskrift for Den norske legeforening 2020. Lastet ned fra tidsskriftet.no 